\title{
Changes in Exercise Habits of University Students During the Covid-19 Lockdown
}

\author{
Deborah Van Langen $^{\mathrm{a}, *}$, Alexander Generali ${ }^{\mathrm{a}}$ \\ a Department of Exercise, Health, and Sport Sciences, University of Southern of Maine, USA \\ *Corresponding author Email: deborah.van1@maine.edu \\ DOI: https://doi.org/10.34256/ijpefs2145 \\ Received: 01-10-2021, Revised: 08-11-2021; Accepted: 12-11-2021; Published: 16-11-2021
}

\begin{abstract}
The purpose of this investigation was to investigate how the exercise habits of college students changed during the COVID-19 pandemic lockdown. Data were collected via an online survey distributed through the University of Southern Maine student email distribution list. All current university students were invited to participate in the survey starting in February 2021 through March 2021. The study included a questionnaire designed to capture the exercise habits of university students three months before the lockdown of COVID-19 (January - March 2020) and their exercise habits after a lockdown in (February - April 2021). The survey questions were based on the American College of Sports Medicine (ACSM) physical activity guidelines to analyze the participant's exercise habits. The participants showed a decrease in the exercise along with an increase in weekly sitting time. Before COVID-19, $21.8 \%$ of participants were sitting $>35$ hours per week. After the COVID-19 lockdown, $50.45 \%$ of participants were sitting $>35$ hours per week. The results of this study could be used for further research to promote an increase in exercise at home. With the uncertainty of the pandemic, motivating people to stand and walk more could be the first step in breaking the increase in sitting habits and help to increase exercise habits. The COVID-19 pandemic has indeed imposed many restrictions on our daily routines, but it could also guide us to new approaches for prescribing exercise programs in the future.
\end{abstract}

Keywords: COVID-19, Physical activity, Exercise, lockdown, Increase sitting
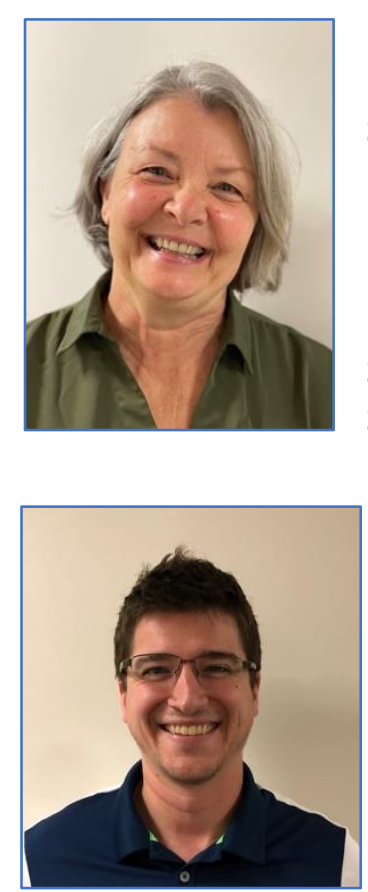

Deborah Van Langen has a Ph.D. in Exercise Physiology from Springfield College, Springfield, MA and is the Exercise Science Program Director and Assistant Professor in the Department of Exercise, Health, and Sport Sciences at the University of Southern Maine, Gorham, USA.

Alexander Generali has his master's degree in Exercise Science from SUNY Cortland, Cortland N.Y. and is a Lecturer in the Department of Exercise, Health, and Sports Sciences at the University of Southern Maine, Gorham, Maine, USA.

\section{Introduction}

The Coronavirus pandemic 2019 (COVID-19) is a new virus that has swept through over 100 countries. In early 2019, many countries downplayed the threat of the virus and referred to it as the common cold $[1,2]$. With a high infection rate and limited resources, COVID-19 has had catastrophic consequences and has revealed inequities in our healthcare system. Across the world, public health measures such as social distancing, travel restrictions, curfews, and school closures, handwashing, and mask mandates, put unprecedented restrictions on all citizens [3-5].

A population of particular concern is college students who were forced off-campus and into an online learning world [6]. While all these public health measures were essential in reducing the spread of the virus, other factors surfaced, such as boredom, frustration, and unhealthy routines [7, 8]. The unprecedented level of restriction to their lives over the 
past year and a half has also presented a barrier to exercise. However, restrictions vary from state to state, the general population of college students were forced off campus needing to seek alternative exercise programs or risk the termination of their exercise routine. Looking for a new way to stay active has presented an opportunity to review how exercise is currently prescribed and review alternative ways to promote safe exercise programs at home [9].

The COVID-19 restrictions limited access to athletics, gyms, group exercise, and leisure time activities [10]. Results of a 2020 global survey by Ammar et al, 2020 showed that days per week physical activity decreased by $24 \%$ and hours sitting increased by $28.6 \%$ due to home confinement. In addition, vigorous intensity activity decreased by $22.7 \%$ and moderate activity decreased by $24 \%$. These results indicate that the COVID-19 confinement has increased sedentary behavior and a decrease in all levels of physical activity [10].

In a 2019 national survey, 22.3\% of surveyed students reported engaging in moderate-intensity cardio or aerobic activity for at least 30 minutes 0 days per week, $56.2 \%$ reported $1-4$ days, and $21.2 \%$ reported $5-7$ days a week. $43 \%$ of surveyed students reported engaging in vigorous-intensity cardio or aerobic activity for at least 20 minutes 0 days per week, $30.6 \%$ saying $1-4$ days, and $26.3 \%$ report $5-7$ days a week [11]. This is of concern because physical activity recommendation from the American College of Sports Medicine and the American Heart Association 2018 that state all healthy adults ages 18-65 should engage in moderate-intensity cardio or aerobic exercise for at least 30 minutes on 5 or more days per week, or vigorous-intensity cardio or aerobic exercise for at least 20 minutes on 3 or more days per week [12].

The American College of Sports Medicine (ACSM) recommendation for moderate cardiovascular physical activity is $5 x$ per week or at least 150 mins at $40-60 \%$ heart rate reserve or $2-3 x$ per week or at least 40-60 minutes at $\geq 60 \%$ heart rate reserve. Their recommendation for muscle strengthening activity is 2$3 x$ per week, 2-4 sets, 8-25 reps at $60-80 \% 1$ RM of multi-joint full body movements [12]. Although during the pandemic lockdown, these guidelines were challenging, ACSM recommended still trying to maintain 30-60 minutes of physical activity on most days with continued social distancing. An adapted physical activity routine may include being creative outdoors, home workouts, or alternative times. Developing new approaches to physical activity will help improve mental health and reduce anxiety and depression $[9,13]$.

The present study aimed to investigate how the exercise habits of college students changed as a result of the COVID-19 pandemic lockdown. This survey compared exercise habits three months before the lockdown and within two months after the lockdown was lifted. The researchers hypothesized that the limitations of the lockdown would decrease exercise in those exercising before the lockdown and exercise would increase in those who were not exercising prior to the lockdown. It was also hypothesized that all respondents would have an increase in sitting time. Data were collected from students via an online survey distributed through a university student email distribution list.

\section{Materials and Methods}

\subsection{Participants}

All university students, including undergraduates, graduates, and alumni, were invited to participate in the online survey from February 2021 through March 2021. The participants were recruited through the university student email distribution lists. Participation in this study was voluntary and they had to have a current university email to receive the survey. Inclusion criteria were a) must be 18 yrs or older; b) current student of USM; and c) able to give consent. The study was approved by the Institutional Review Board of the University of Maine.

\subsection{Software}

The information was collected by an electronic survey using the Qualtrics platform and was kept confidential and anonymous. The survey was shared through the university's student email distribution list. The survey was divided into three sections: informed consent, exercise and sitting habits, and demographics.

\subsection{Procedures}

The study included a questionnaire designed to capture the exercise habits of university students three months prior to the lockdown of COVID-19 (January 2020 - March 2020) and their exercise habits two months after lockdown (February 2020 - April 2021). The survey questions were based on the current American College of Sports Medicine (ACSM) physical activity guidelines, including several days a week exercising, a combination of moderate and vigorous 
activity, aerobic and strength activities, and hours of sitting. We understand that the working definitions of exercise and PA are a limitation of this study. In this study, they will be used interchangeability.

\subsection{Statical Analysis}

The survey instrument included pairs of questions, each containing one question related to before COVID19 lockdown and another pertaining to current post lockdown. New variables were computed by comparing these pairs to determine if exercise had decreased, remained the same, or increased over time. The analysis performed for this study included frequencies to summarize each survey question's distribution across answer categories. Frequencies were also run for the new change variables and were used to look for differences between exercise subpopulations for each changing variable.

\section{Results}

Table 1 shows a total $(n=548)$ participants including ( $n=126$ male, $n=401$ female, $n=14$ nonbinary, $n=3$ not listed, and $n=4$ prefer not to say) ages 18 yrs to $60+$ yrs participated in the survey.
All participants were current students from the University of Southern Maine and had a current student email address. Current job status could have multiple answers for one participant and included $(n=$ 147 full-time, $n=256$ part-time, $n=103$ unemployed, $\mathrm{n}=72$ seeking opportunities, $\mathrm{n}=32$ not seeking opportunities, $\mathrm{n}=7$ retired, and $\mathrm{n}=6$ alumni). Marital status showed ( $n=116$ married, $n=398$ not married, and $n=30$ with domestic partners).

\section{Days per Week of Aerobic Exercise}

Respondents $(n=515)$ were asked how many days a week they participated in aerobic exercise before the COVID-19 lockdown. They were presented with four answer categories: 0 days, 1-2 days, 3-4 days, and $\geq 5$ days. Figure 1 shows that the most frequently used response category was 3-4 days, with $(n=185)$ respondents choosing this answer. The next frequently used response category was 1-2 days at ( $\mathrm{n}$ $=180)$ followed by $\geq 5$ days at $(n=110)$ and 0 days at $(n=40)$. Respondents were also asked how many days a week they participate in aerobic exercise after the COVID-19 lockdown.

Table 1. Demographic Characteristic of Participants

\begin{tabular}{|c|c|c|c|}
\hline Variables & & $n=(548)$ & $\%$ \\
\hline \multirow[t]{5}{*}{ Gender } & Male & 126 & $23 \%$ \\
\hline & Female & 401 & $73 \%$ \\
\hline & Non-binary & 14 & $2.6 \%$ \\
\hline & Not listed & 3 & $0.5 \%$ \\
\hline & Prefer not to say & 4 & $0.7 \%$ \\
\hline \multirow[t]{4}{*}{ Age (yrs) } & $18-30$ & 392 & $71.7 \%$ \\
\hline & $31-44$ & 91 & $16.6 \%$ \\
\hline & $45-59$ & 57 & $10.4 \%$ \\
\hline & $\geq 60$ & 7 & $1.3 \%$ \\
\hline \multirow[t]{7}{*}{ Job Status } & Employed full-time & 147 & $27 \%$ \\
\hline & Employed part-time & 256 & $47 \%$ \\
\hline & Unemployed & 103 & $19 \%$ \\
\hline & Seeking opportunities & 72 & $13 \%$ \\
\hline & Not seeking opportunities & 32 & $6.0 \%$ \\
\hline & Retired & 7 & $1.0 \%$ \\
\hline & Alumni & 6 & $1.0 \%$ \\
\hline \multirow[t]{4}{*}{ Marital Status } & Yes & 116 & $21.2 \%$ \\
\hline & No & 398 & $72.6 \%$ \\
\hline & Domestic partnership & 30 & $5.5 \%$ \\
\hline & Prefer not to say & 0 & $0 \%$ \\
\hline
\end{tabular}


They were presented with the same answer categories. The most frequently used response category was 1-2 days, with $(n=182)$ respondents choosing this category. The next frequently used response category was 3-4 days at $(n=121)$ followed by $\geq 5$ days at $(n=113)$ and 0 days at $(n=99)$

The changing variable computed from the responses to these two questions shows that the largest segment of respondents $(41.7 \%)$ experienced a decrease in exercise, followed by those who reported the same level of exercise (32.8\%) and those who increased exercise (25.4\%).

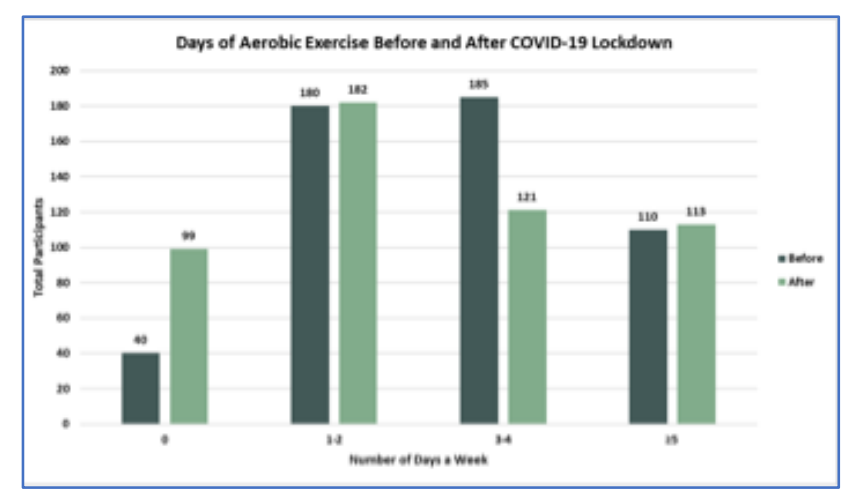

Figure 1. Comparison of days of aerobic exercise per week in college students $(n=515)$ between before and after COVID-19 lockdown.

\section{Minutes per Week of Aerobic Exercise}

Respondents $(n=514)$ were asked how many minutes a week they participated in aerobic exercise before the COVID-19 lockdown. They were presented with five answer categories: 0 minutes, 1-50 minutes, 51-100 minutes, 101-150 minutes and $\geq 150$ minutes. Figure 2 shows that the most frequently used response category was 51-100 minutes, with $(n=144)$ respondents choosing this answer. The next frequently used response category was 1-50 minutes at $(n=124)$ followed by $\geq 150$ minutes at $(n=106)$ then 101-150 minutes at $(n=99)$ and 0 minutes at $(n$ $=41$ ).

Respondents were also asked how many minutes a week they exercised they participated in aerobic exercise after the COVID-19 lockdown. They were presented with the same answer categories. The most frequently used response category was $51-100$ minutes, with $(n=120)$ respondents choosing this category. The next frequently used response category was $1-50$ minutes at $(n=110)$ followed by 0 minutes at $(n=99)$ then $\geq 150$ minutes at $(n=98)$ and 101150 minutes at $(n=87)$
The changing variable computed from the responses to these two questions shows that the largest segment of respondents (38.6\%) remained the same, followed by those who decreased their minutes of exercise per week (38.2\%) and those who increased exercise (23.2\%).

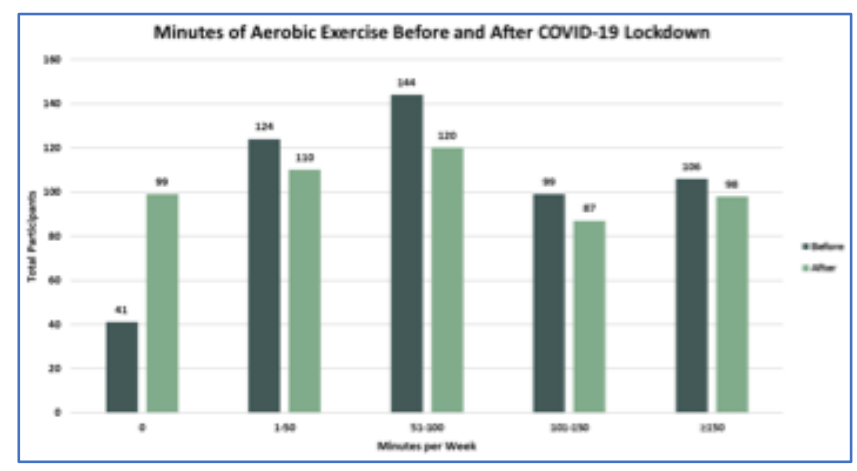

Figure 2 Comparison of minutes of aerobic exercise per week in college students $(n=514)$ between before and after COVID-19 lockdown.

\section{Number of Days per Week of Muscular Strength Exercise}

Respondents ( $n=516)$ were asked how many days a week they engaged in muscle strengthening exercise before the COVID-19 lockdown. They were presented with four answer categories: 0 days, 1-2 days, 3-4 days, and $\geq 5$ days. Figure 3 shows that the most frequently used response category was 1-2 days, with $(\mathrm{n}=170)$ respondents choosing this category. The next frequently used response category was 0 days at $(n=162)$ followed by 3-4 days at $(n=$ 133) and $\geq 5$ days at $(n=51)$.

Respondents were also asked how many days a week they engaged in muscle strengthening exercise after the COVID-19 lockdown. They were presented with the same answer categories. The most frequently used response category was 0 days, with ( $n$ $=187$ ) respondents choosing this answer. The next frequently used response category was 1-2 days at ( $n$ $=150)$ followed by $3-4$ days at $(n=120)$ and $\geq 5$ days at $(\mathrm{n}=59)$.

The changing variable computed from the responses to these two questions shows that the largest segment of respondents (43.2\%) continued the same level of exercise, followed by those who reported a decrease in exercise $(29.8 \%)$ and those who increased exercise (26.9\%). 


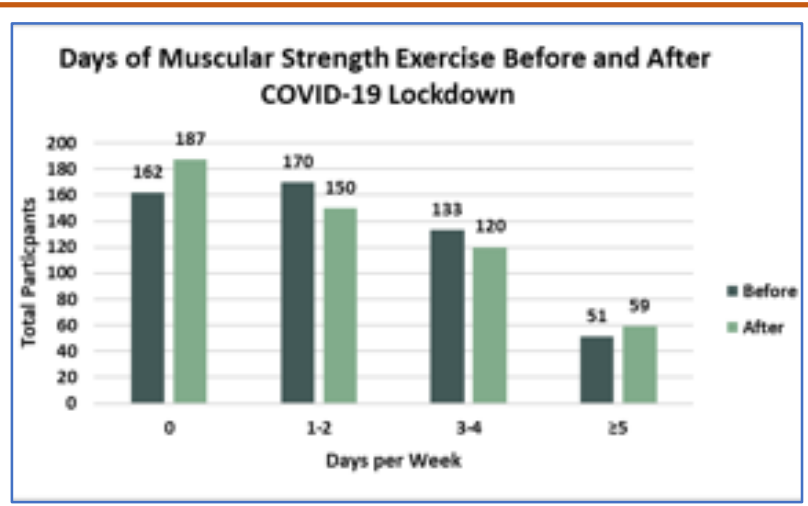

Figure 3. Comparison of days per week of muscle strengthening exercise per week in college students ( $n$ $=516$ ) between before and after COVID-19 lockdown.

\section{Number of Hours per Week of Sitting}

Respondents ( $n=545$ ) were asked how many hours a week they spent sitting before the COVID-19 lockdown. They were presented with four answer categories: < 10 hours, 11-25 hours, 26-35 hours, and $>35$ hours. Figure 4 shows that the most frequently used response category was 11-25 hours, with ( $\mathrm{n}=$ 195) respondents choosing this category. The next frequently used response category was $26-35$ hours at $(n=183)$ followed by $>35$ hours at $(n=119)$ and $<10$ hours at $(n=48)$.

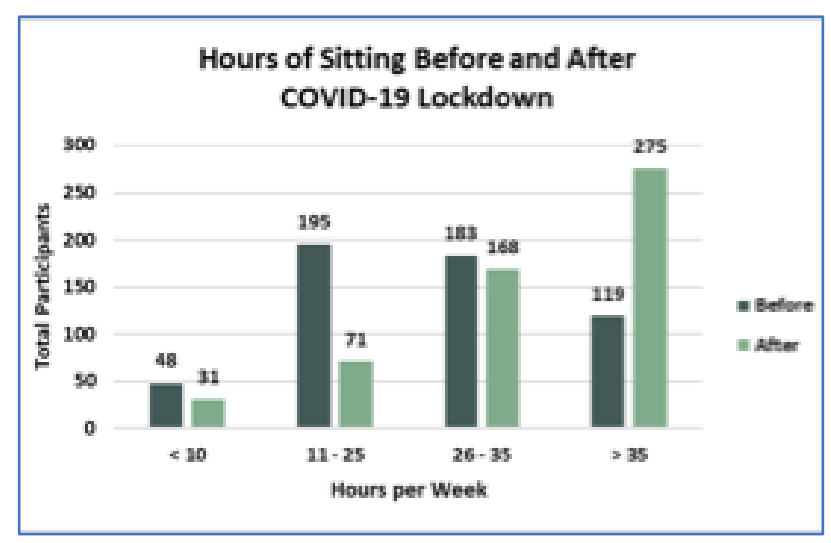

Figure 4. Comparison of hours per week of sitting in college students $(n=545)$ between before and after COVID-19 lockdown.

Respondents were also asked how they spent sitting after the COVID-19 lockdown. They were presented with the same answer categories. The most frequently used response category was $>35$ hours ( $n$ $=275$ ). The next frequently used category was $26-35$ hours $(n=168)$, followed by $11-25$ hours $(n=71)$ and $<10$ hours $(n=31)$.

The changing variable computed from the responses to these two questions shows that the largest segment of respondents (49.7\%) increased the number of hours they spent sitting, followed by those who reported staying the same $(43.5 \%)$ and those who decreased $(6.8 \%)$.

\section{Exercise Habits Before and After COVID-19 Lockdown}

Responses to the exercise habits and sitting behavior before and after the COVID-19 lockdown. Table 2 below includes the proportion of those who decreased, stayed the same, and increased in the various types of exercise studied. This was computed by comparing the categories reported before the COVID-19 lockdown and those reported after the COVID-19 lockdown. The authors acknowledge that there are limitations to this approach because survey responses were categorical rather than numeric.

\section{Discussion}

This study aimed to investigate how the exercise habits of college students changed before and after the COVID-19 pandemic lockdown. The researchers compared exercise habits three months prior to the lockdown and within two months after the lockdown was lifted. The researchers hypothesized that the limitations of the lockdown would decrease exercise in those exercising prior to the lockdown and exercise would increase in those who were not exercising prior to the lockdown. It was also hypothesized that all respondents would have an increase in sitting time.

The results showed a negative impact from the lockdown on all exercise, including moderate, vigorous, and muscle strengthening in participants. In addition, as expected, there was a substantial increase of hours of sitting per week. The study's findings confirmed our hypothesis that a number of participants changed their exercise habits due to the pandemic and had an increase in hours per week of sitting time.

Despite the public health recommendations to continue healthy behaviors during the COVID-19 lockdown, the confinement and social distancing limit all daily activities, exercise, and social activities. The increase in inactivity and sedentary behavior has shown to have numerous adverse effects on health, physical fitness, and mental wellbeing [14-16]. The loss of a regular routine coupled with financial nervousness and loneness only added to a lack of motivation to continue daily activities [17]. In contrast, some researchers found that the lockdown increased sitting time and increased physical activity time. 
Table 2. Responses to the exercise habits survey before and after the COVID-19 lockdown

\begin{tabular}{|c|c|c|c|c|c|c|}
\hline & & $\begin{array}{c}\text { Before } \\
\text { Lockdown }\end{array}$ & $\begin{array}{c}\text { After } \\
\text { Lockdown }\end{array}$ & $\%$ Decreased & $\%$ Stayed the same & $\%$ Increased \\
\hline \multirow[t]{11}{*}{ All PA } & Days/week & & & & & \\
\hline & 0 & 65 & 125 & & $46.0 \%$ & $54.0 \%$ \\
\hline & $1-2$ & 144 & 131 & $32.0 \%$ & $22.0 \%$ & $47.0 \%$ \\
\hline & $3-4$ & 186 & 146 & $56.0 \%$ & $32.0 \%$ & $12.0 \%$ \\
\hline & $\geq 5$ & 146 & 139 & $46.0 \%$ & $54.0 \%$ & \\
\hline & Min/week & & & & & \\
\hline & 0 & 66 & 126 & & $45.5 \%$ & $54.5 \%$ \\
\hline & 1 to 50 & 98 & 93 & $27.6 \%$ & $30.6 \%$ & $41.8 \%$ \\
\hline & $51-100$ & 131 & 99 & $51.2 \%$ & $22.5 \%$ & $26.4 \%$ \\
\hline & $101-150$ & 99 & 90 & $53.1 \%$ & $31.6 \%$ & $15.3 \%$ \\
\hline & $\geq 150$ & 154 & 136 & $41.2 \%$ & $58.8 \%$ & \\
\hline \multicolumn{7}{|l|}{ Aerobic } \\
\hline \multirow[t]{11}{*}{ Exercise } & Days/week & & & & & \\
\hline & 0 & 40 & 99 & & $22.5 \%$ & $77.5 \%$ \\
\hline & $1-2$ & 180 & 182 & $28.9 \%$ & $33.9 \%$ & $37.2 \%$ \\
\hline & $3-4$ & 185 & 121 & $56.8 \%$ & $25.4 \%$ & $17.8 \%$ \\
\hline & $\geq 5$ & 110 & 113 & $52.7 \%$ & $47.3 \%$ & \\
\hline & Min/week & & & & & \\
\hline & 0 & 41 & 99 & & $22.0 \%$ & $78.0 \%$ \\
\hline & 1 to 50 & 124 & 110 & $27.4 \%$ & $39.5 \%$ & $33.1 \%$ \\
\hline & $51-100$ & 144 & 120 & $44.4 \%$ & $30.6 \%$ & $25.0 \%$ \\
\hline & $101-150$ & 99 & 87 & $49.5 \%$ & $30.3 \%$ & $20.2 \%$ \\
\hline & $\geq 150$ & 106 & 98 & $47.2 \%$ & $52.8 \%$ & \\
\hline \multicolumn{7}{|l|}{ Moderate } \\
\hline \multirow[t]{11}{*}{ Intensity } & Days/week & & & & & \\
\hline & 0 & 74 & 123 & & $54.1 \%$ & $45.9 \%$ \\
\hline & $1-2$ & 185 & 181 & $26.5 \%$ & $40.5 \%$ & $33.0 \%$ \\
\hline & $3-4$ & 155 & 117 & $59.4 \%$ & $31.0 \%$ & $9.7 \%$ \\
\hline & $\geq 5$ & 99 & 92 & $48.5 \%$ & $51.5 \%$ & \\
\hline & Min/week & & & & & \\
\hline & 0 & 147 & 214 & & $64.6 \%$ & $35.4 \%$ \\
\hline & 1 to 50 & 105 & 88 & $45.7 \%$ & $38.1 \%$ & $16.2 \%$ \\
\hline & $51-100$ & 103 & 94 & $52.4 \%$ & $28.2 \%$ & $19.4 \%$ \\
\hline & $101-150$ & 94 & 61 & $53.2 \%$ & $30.9 \%$ & $16.0 \%$ \\
\hline & $\geq 150$ & 67 & 59 & $47.8 \%$ & $52.2 \%$ & \\
\hline \multicolumn{7}{|l|}{ Vigorous } \\
\hline \multirow[t]{6}{*}{ Intensity } & Days/week & & & & & \\
\hline & 0 & 147 & 214 & & $64.6 \%$ & $35.4 \%$ \\
\hline & $1-2$ & 191 & 153 & $43.5 \%$ & $36.1 \%$ & $20.4 \%$ \\
\hline & $3-4$ & 121 & 95 & $52.9 \%$ & $35.5 \%$ & $11.6 \%$ \\
\hline & $\geq 5$ & 57 & 54 & $50.9 \%$ & $49.1 \%$ & \\
\hline & $\begin{array}{r}\text { Min/week } \\
0\end{array}$ & 147 & 214 & & $64.6 \%$ & $35.4 \%$ \\
\hline
\end{tabular}




\begin{tabular}{rccccc}
1 to 50 & 105 & 88 & $45.7 \%$ & $38.1 \%$ & $16.2 \%$ \\
$51-100$ & 103 & 94 & $52.4 \%$ & $28.2 \%$ & $19.4 \%$ \\
$101-150$ & 94 & 61 & $53.2 \%$ & $30.9 \%$ & $16.0 \%$ \\
$\geq 150$ & 67 & 59 & $47.8 \%$ & $52.2 \%$ & \\
\hline
\end{tabular}

\begin{tabular}{lrrcccc}
\hline $\begin{array}{l}\text { Muscle } \\
\text { Strengthening }\end{array}$ & Days/week & & & & & \\
& 0 & 162 & 187 & & $55.6 \%$ & $44.4 \%$ \\
& $1-2$ & 170 & 150 & $30.6 \%$ & $38.2 \%$ & $31.2 \%$ \\
& $3-4$ & 133 & 120 & $53.4 \%$ & $36.1 \%$ & $10.5 \%$ \\
& $\geq 5$ & 51 & 59 & $60.8 \%$ & $39.2 \%$ & \\
\hline Sitting & & & & & & \\
hrs/week & 10 & 48 & 31 & & $41.7 \%$ & $58.3 \%$ \\
& $11-25$ & 195 & 71 & $4.6 \%$ & $21.0 \%$ & $74.4 \%$ \\
& $26-35$ & 183 & 168 & $7.1 \%$ & $39.3 \%$ & $53.6 \%$ \\
& $>35$ & 119 & 275 & $12.6 \%$ & $87.4 \%$ & \\
\hline
\end{tabular}

Romero-Blanco et al., 2020 found that health science students spent more time sitting and more time participating in physical activity. Despite not having access to a gym, group activities, or social activities, the number of days and minutes per week increased. This increase in physical activity in this group was attributed to the possibility that the health science curriculum could have influenced their decision that promoted health habits [18].

Saňudo et al., 2020 concluded that home quarantine affected physical activity, sedentary behavior, smartphone use, and sleep patterns. Researchers concluded that participants spend less time being active and more time sitting than a greater number that met the physical activity guidelines prior to the lockdown [18]. Ammar et al., 2020 reported decreases in vigorous and moderate activity along with an increase in daily sitting time. This study concluded that the reduction of physical activity could contribute to a growth in physical health problems long term and continued research is needed [19].

These survey results showed similarities with other researchers that demonstrated that the COVID19 pandemic had an impact on daily routines, including athletic sports and exercise [19, 20]. Even among more technically savvy college students and with the increased availability of physical activities programs online, this did not help maintain adequate exercise levels. Participating in exercise at home can have limitations. The selection of a new exercise routine may require experience and knowledge. Although home exercise programs can support decreasing sedentary activity, they are not appropriate for everyone.
Individuals, family, and friends should take caution when participating or suggesting an activity to someone else [21].

In general, the results were seen in table 2 establish a similar trend of a decrease in exercise and an increase in hours sitting between groups. One of the most notable increases was observed in the group reporting "0 days" or "0 minutes," showing that more individuals were not exercising at all during the pandemic. Another notable increase was in the number of hours sitting per week, with those reporting sitting $>35$ hours per week more than doubling during the pandemic. This general decrease in activity and increase in hour sitting can lead to many adverse side effects as this trend increases the risk of developing comorbidities [22, 23].

In this population, a large percentage were not participating in muscle strengthening exercises prior to the lockdown and did not engage in any muscle strengthening activity post lockdown. Conducting home-based exercises can be difficult and unsafe. As a result, exercise prescription is challenging when establishing a muscle strengthening program at home [21]. Since this is not a novel topic and positive benefits have been reported, no specific guidelines have been established for home-based activity [9].

Finally, it is important to realize that motivating college students to stay physically active and social engagement was difficult during the COVID-19 lockdown. Home confinement altered normalcy with respect to education, work, family, friends, exercise, and sedentary behavior. These results were consistent with similar studies and that the COVID-19 lockdown 
has been described as a worldwide public health risk [24].

\section{Conclusion}

The results of this study should be used for further research to promote an increase in exercise at home. With the uncertainty of the pandemic, motivating people to stand and walk more could be the first step in breaking the increase in sitting habits and help to increase exercise. The COVID-19 pandemic has certainly imposed many restrictions on our daily activities, but it could also help develop new approaches for prescribing exercise in the future. One important consideration for working with clients remotely is safety. Within a virtual setting, a no-touch approach will be challenging to monitor heart rate, blood pressure, cardiovascular symptoms and not be able to spot clients while exercising. This is a new area in our field that will need to be explored in more detail.

\section{References}

[1] F.A. Barwais, Assessing Physical Activity and Sedentary Time During the COVID-19 Pandemic Using Self-Reported Measurements, National Journal of Physiology, Pharmacy, and Pharmacology, 10(11) (2020) 1019-1024. [DOI]

[2] J.A. Woods, N.T. Hutchinson, S.K. Powers, W.O. Roberts, M.C. Gomez-Cabrera, Z. Radak, I. Berkes, A. Boros, I. Boldogh, C. Leeuwenburgh, H.J. Coelho-Júnior, E. Marzetti, Y. Cheng, J. Liu, J.L. Durstine, J. Sun, L.L. Ji, The COVID-19 Pandemic and Physical Activity, Sports Medicine and Health Science, 2(2) (2020) 55-64. [DOI] [PubMed]

[3] K.E. Coakley, D.T. Lardier, K.R. Holladay, F.T. Amorim, Physical Activity Behavior and Mental Health Among University Students During COVID-19 Lockdown, Frontiers in Sports and Active Living, 682175(3) (2021) 1-8. [DOI] [PubMed]

[4] T. Hwang, Coronavirus Lockdown and Virus Suppression: An International Analysis, Technological Forecasting \& Social Change, 170(120861) (2021) 1-16. [DOI]

[5] M.A. Faghy, R. Arena, L. Stoner, R.H. Haraf, R. Josephson, A. P. Hills, S. Dixit, D. Popovic, A. Smith, J. Myers, S.L. Bacon, J. Neibauer, V.Z. Dourado, A.S. Babu, T.M. Maden-Wilkinsson, R.J. Copeland, L.A. Gough, S. Bond, K. Stuart,
T. Bewick, R.E.M. Ashton, on behalf of the PIVOT network, The Need for Exercise Science and an Integrated Response to COVID-19: A Position Statement From the International HLPIVOT network, Progress in Cardiovascular Diseases, 67 (2021) 2-10. [DOI] [PubMed]

[6] M. Barry, L. Ghonem, A. Alsharidi, A. Alanazi, N.H. Alotaibi, F.S. AlShahrani, F. Al Majid, A.S. BaHammam, Coronavirus Disease 2019 Pandemic in the Kingdom of Saudi Arabia: Mitigation Measures and Hospital Preparedness, Journal of National Science of Medicine, 3(13) (2020) 155-158. [DOI]

[7] A.Y.Y. Wong, S.K.K. Ling, L.H.T. Ling, L.H.T. Louie, G.Y.K. Law, R.C.H. So, D.C.W. Lee, F.C.F. Yau, P.S.H. Yung, Impact of the COVID19 Pandemic on Sports and Exercise, AsiaPacific Journal of Sports Medicine, Arthroscopy, Rehabilitation and Technology, 22 (2020) 3944. [DOI] [PubMed]

[8] C. Romero-Blanco, J. Rodríguez, M.D. OnievaZafra, M.L. Parra-Fernández, M.C. PradoLaguna, A. Hernández-Martínez, Physical Activity and Sedentary Lifestyle in University Students: Changes During Confinement Due to the COVID-19 Pandemic, International Journal of Environmental Research and Public Health, 17(6567) (2020) 3-13. [DOI] [PubMed]

[9] K.L. Denay, R.G. Breslow, M. N. Turner, M. N. Nieman, D. C. Nieman, W. O. Roberts, T.M. Best, ACSM Call to Action Statement: COVID19 Considerations for Sports and Physical Activity. Current Sports Medicine Reports, 19(8) (2020) 326-328. [DOI] [PubMed]

[10] Ammar, M. Brach, K. K. Trabelsi, H. Chtourou, O. Boukhris, L. Masmoudi, B. Bauaziz, D. How, M. Ahmed, P. Müller, N. Müller, A. Aloui, O. Hammouda, L.L. Paineiras-Domingos, A. Braakman-Jansen, C. Wrede, S. Bastoni, C.S. Pernambuco, L. Mataruna, M. Taheri, K. Irandoust. A. Khacharem, M.L. Bragazzi, K. Chamari, J. M. Glenn, M.T. Bott, F. Gargouri, L. Chaari, H. Batatia, G. M. Ali, O. Abdelkarim, M. Jarray, K.E. Abed, M. Souissi, L.V. GemertPijnen, B.L. Reimann, L. Riemann, W. Moalla, J. Gómez-Raja, M. Epstein, R. Sanderman, S.V.W. Schulz, A. Jerg, R. Al-Horani, T. Mansi, M. Jmail, F. Barbosa, F. Ferreira-Santos, B. Šimunič, R. Pišot, A. Gaggioli, S.J. Bailey, J.M. Steinacker, T. Driss, A. Hoekelmann. on behalf of the ECLB-COVID-19 Consortium, Effects of COVID-19 Home Confinement on Eating 
Behavior and Physical Activity: Results of the ECLB-COVID19 International Online Survey, Nutrients, 12(6):1583 (2020) 5-13. [DOI] [PubMed]

[11] American College Health Association. American College Health Association-National College Health Assessment II: Reference Group Executive Summary Spring 2019. Silver Spring, MD: American College Health Association; (2019) 1-19. Retrieved: https://www.acha.org/documents/ncha/NCHAII_SPRING_2019_US_REFERENCE_GROUP_EX ECUTIVE_SUMMARY.pdf

[12] D. Reibe, J.K. Ehrman, G. Liguori, M. Magal, (2018), ACSM's Guidelines for Exercise Testing and Prescription $\left(10^{\text {th }}\right)$, Wolters Kluwer Publishing, Philadelphia, PA, USA.

[13] B. Constandt, E. Thibaut, V. De Bosscher, J. Scheerder, M. Ricours, A. Willem, Exercising in Times of Lockdown: An Analysis of the Impact of COVID-19 on Levles and Patterns of Exercise Among Adults in Belgium, International Journal of Environmental Research and Public Health, 7(11) (2020) 3-10. [DOI] [PubMed]

[14] C.E. Garber, B. Blissmer, M.R. Deschenes, B.A. Franklin, M.J. Lamonte, I.M. Lee, D.C. Nieman, D.P. Swain, Quantity and quality of exercise for developing and maintaining cardiorespiratory, musculoskeletal, and neuromotor fitness in apparently healthy adults: guidance for prescribing exercise, Medicine \& Science in Sports \& Exercise, 43(7) (2011) 1334-1359. [DOI] [PubMed]

[15] V. Giustino, A.M. Parroco, A. Gennro, G. Musumeci, A. Palma, G. Battaglia, Physical Activity Levels and Related Energy Expenditure During COVID-19 Quarantine Among the Sicilian Active Population: A Cross-Sectional Online Survey Study, Sustainability, 12(11) (2020) 3-19. [DOI]

[16] S. Hu, L. Tucker, C. Wu, L. Yang, Beneficial Effects of Exercise on Depression and Anxiety During the COVID-19 Pandemic: A Narrative Review, Frontiers in Psychiatry, (11):587557 (2020). [DOI] [PubMed]

[17] F. Galle, E. A. Sabella, S. Ferracuti, O. De Giglio, G. Caggiano, C. Protano, F. Valeriani, E. A. Parisi, G. Valerio, G. Liguori, M. T. Montagna, V. R. Spica, G. Da Molin, G. B. Orsi, C. Napoli, Sedentary Behavior and Physical Activity of Italian Undergraduate Students
During Lockdown at the Time of COVID-19 Pandemic, International Journal of Environmental Research and Public Health, 17(17): 6171 (2020) 3-11. [DOI] [PubMed]

[18] B. Saňudo, C. Fennell, A.J. Saňchez-Oliver, Objectively-Assessed Physical Activity, Sedentary Behavior, Smartphone Use, and Sleep Patterns Pre and During COVID-19 Quarantine in Young Adults from Spain, Sustainability, 12(15): 5890 (2020) 5-12. [DOI]

[19] Ammar, H. Chtourou, O. Boukhris, K. Trabelsi, L. Masmoudi, M. Brach, B. Bouaziz, E. Bentlage, D. How, M. Ahmed, P. Mueller, N. Mueller, A. Aloui, O. Hammouda, L.L. Paineiras-Domingoes, A. Braakmanjansen, C. Wrede, S. Bastoni, C.S. Pernambuco, L. Mataruna, M. Taheri, K. Irandoust, A. Khacharem, N.L. Brafazzi, K. Chamari, S.J. Bailey, N.T. Bott, F. Gargouri, L. Chaari, H. Batatia, G.M. Ali, O. Abdelkarim, M. Jarray, K. e. Abed, N. Souissi, L. Van Gemert-Pijnen, B. L. Reimann, L. Reimann, W. Moalla, J. GómezRaja, M. Epstein, R. Sanderman, S. Schulz, A. Jerg, R. Al-Horani, T. Mansi, F. Barbosa, F. Santos, B. Šimunič, R. Pišot, D. Cowan, A. Gaggiol, J.M. Glenn, J. Steinacker, T. Driss, A. Hoekelmann, Social participation and life satisfaction of peoples during the COVID-19 home confinement: the ECLB-COVID19 multicenter study, Preliminary results of the ECLB-COVID19 international online-survey medRxiv, (2020) [DOI]

[20] L. N. Oliveira, H. M. Elsangedy, V. D. O. Travares, C. V. L. S. TeiS. Teia, D. G. Behm, M. E. Silva-Grigoletto, Training at home during the COVID-19 (SARS-COV2) Pandemic: Physical Exercise and Behavior-Based Approach, 19(2) (2020) 1-13. [DOI]

[21] D. C. de Sá-Caputo, R. Taiar, A. Seixas, B. Sanudo, A. Sonza, M. Bernardo-Filho, A Proposal of Physical Performance Tests Adapted as a Home Workout Option During the COVID-19 Pandemic, Applied Sciences, 10(14) (2020) 5-17. [DOI]

[22] E. Bentlage, A. Ammar, D. How, M. Ahmed, K. Trabelsi, H. Chtourou, M. Brach, Practical Recommendations for Maintaining Active Lifestyle During the COVID-19 Pandemic: A Systematic Literature Review, International Journal of Environmental Research and Public Health, 17(17) (2020) 3-22. [DOI] [PubMed]

[22] P.T. Katzmarzyk, K.P. Kennith, M.M. Jakicic, R.P. Troiano, K. Piercy, B. Tennant, Sedentary 
Behavior and Health: Updated From the 2018

Physical Activity Guidelines Advisory Committee, Medicine \& Science in Sports \& Exercise, 51(6) (2019) 1227-1241. [DOI] [PubMed]

[23] R. Guthold, G.A. Stevens, L.M. Riley, F.C. Bull, Worldwide Trends in Insufficient Physical Activity from 2001-2016: A Pooled Analysis of 358 Population Based Surveys with 19 Million Participants, Lancet Global Health, (10):e1077 (2018) 1-33. [DOI] [PubMed]

\section{Acknowledgement}

The authors wish to acknowledge the Survey Research Center staff at Cutler Institute for Health and Social Policy for their assistance with survey design, survey implementation, and data analysis.

\section{Funding}

No funding was received to carry out this study

\section{Authors Contribution}

Both the authors equally contributed to this work. Both of them read and approved the final version of the draft.

\section{Ethics Approval}

Approval was sought from the institution ethics committee.

\section{Informed Consent}

Written consent was obtained from the participants

\section{Conflict of interest}

The Authors have no conflicts of interest to declare that they are relevant to the content of this article.

\section{Does this article screened for similarity?}

Yes

\section{About The License}

(C) The Author(s) 2021. The text of this article is open access and licensed under a Creative Commons Attribution 4.0 International License 